\title{
Study of the Self-Determined Motivation among Students in the Context of Online Pedagogical Activities
}

\author{
https://doi.org/10.3991/ijet.v15i05.11392 \\ Ghizlane Chemsi $(\bowtie)$ \\ Laboratory in Sciences and Information Communication and Education Technology \\ (LAPSTICE) \\ University Hassan II, Casablanca, Morocco \\ g.chemsilgmail.com \\ Mounir Sadiq, Mohamed Radid, Mohammed Talbi \\ University Hassan II, Casablanca, Morocco
}

\begin{abstract}
This article explores the self-determined motivation of a firstyear students' group in the Ben M'sik Faculty of Science as part of formative assessment in the form of quizzes using the Moodle platform. This evaluation deals particularly with the case of the "Language and Terminology" course. We used Deci and Ryan's (1985, 1991, 2000) [1, 2, 3] Self-Determination Theory (SDT) to better assess motivation in our target audience in this ICT-based learning environment.

The choice of a quantitative research methodology resulted in the administration of a questionnaire at the end of Semester 1 and 2, the latter is based on the motivation scale in education $[4,5]$. The results show that the use of ICTbased formative assessment in university pedagogy appears to energize the selfdetermined motivation among learners.
\end{abstract}

Keywords-Motivation, Self-Determination, Formative assessment, Moodle, ICT, Interactive Quiz.

\section{Context of the Study and Problem}

In a society where an emerging digital economy is developing, ICTs are constantly evolving, enabling collaboration, interaction or individualisation [6]. They offer enormous potential for teaching and learning [7], particularly in terms of performance, competence, motivation and academic success. Several studies have shown that learners show higher motivation for a learning activity that uses ICT than for customary approaches in the classroom [8]. This interest comes from the fact that ICTs can diversify objectives, methods, supports, projects and learning outcomes.

In fact, motivation can be defined as the process by which a goal-directed activity is generated and supported [5]. In the academic environment Karsenti and al. (2001) [9] define motivation as a dynamic state whose origins lie in the perceptions that a learner has of himself/ herself and his/ her environment and which encourages him to 
choose an activity, carry it out and perform it ideally in order to achieve a goal or an objective

In this context, the pedagogical environment and the learning model implemented by both the teacher and the social context are the determinants that are likely to significantly influence his / her behavior and his / her commitment, especially when it comes to a situation of learning marked by the integration of ICT, in this case the learner not only involved in the construction of his / her knowledge, by participating actively through the many digital tools available to him / her, but also develops his /her self-determination [10].

Nowadays, the integration of Information and Communication Technologies (ICT) into the teaching and learning process is no longer an option in the Moroccan higher education system, but it becomes an obligation among the priority measures and projects included in the 2015-2030 reform's strategic vision [11], in order to improve the quality of learning and promote the transition from a knowledge-based society to a society that produces and disseminates it.

From this perspective of improving the quality of student learning and motivation within the Ben M'sik-Casablanca Faculty of Science, particularly the case of the "Language and Terminology" course where students are passive and are not motivated to learn. Our purpose so is to make the teaching of this course dynamic and motivate students. To achieve this, we adopted an innovative educational strategy based on the implementation of interactive quizzes through the tools of the Moodle platform. To deal with this new pedagogical practice, it becomes important to measure the impact of the educational use of interactive formative quizzes on the self-determined motivation of a group of students. To achieve this, we will try to answer the following research question: What influence do interactive quizzes have on the self-determined motivation in students in teaching the Language and Terminology module?

\section{Theoretical Framework}

\subsection{The motivation}

In literature on learning, motivation is a key concept [12]. It can be defined as «a process of action steered towards a goal» [13] (p.5), or, more fully, as a «hypothetical concept representing physiological and psychological processes» [14] (p.215). It is generally characterized by internal and / or external forces that, depending on whether or not a goal-guided context, can influence an individual on different levels (cognitive, emotional or behavioral). This definition indicates the presence of a hypothetical construct and a process triggered by the inner behavior that depends on personal characteristics and by an external motivational force that depends on the environment that encourages him / her to engage, and external to the person himself. The degree of motivation may be «either weak or strong, varying both between individuals at specific times, and at the same person at different times, and depending on the circumstances» [15] (p.8). 
According to Viau (1995) [16], the context in which the student is situated and the way he perceives it determine his motivation which, according to him, is influenced by three types of factors: the interest that the student perceives for the task or the activity to be carried out, its capacity to carry it out and finally the sources of control it holds over its course and its consequences. This idea joins the motivation theory of Deci and Ryan (1985) [1], which shows that a student's motivation is essentially influenced by his needs for self-determination, competence and affiliation.

\subsection{Self-determination theory}

This research concentrates on the self-determination theory developed by Deci and Ryan $(1985,1991,2000)$ [1, 2, 3] who have focused on personality development and behavioral self-motivated change. This is an approach of human motivation and personality which sees every person as an active organism who seeks continuously and naturally to improve his/ her human potential through the discovery of new thoughts, mastery of new skills and satisfaction of his /her requirements [3]. This organism seeks to understand and explain the motivational dynamics and reasons the reasons why people choose to engage or not in an activity and to define the passive, alienated individuals carrying out their activities and / or their tasks mechanically [17]. What distinguishes active individuals from those who are passive is the result of the interaction between the active nature inherent to every individual and the different environments that fill or frustrate it. According to Deci and Ryan (1985) [1], the motivation is considered as self-determined if it reflects the actor's capacity to feel that he is responsible for his choices rather than being determined by internal or external constraints.

\subsection{The different forms of self-determined motivations}

Deci and Ryan (1985) [1] argue that there are different forms of motivation that are differentiated by their degree of self-determination, that is, the degree to which an activity is carried out with a sense of free choice, self-determination and internal consistency. They conceive three major forms of motivation organized along a continuum: intrinsic motivation, extrinsic motivation and amotivation. Each form of motivation is associated with a level of self-determined and autonomous behavior.

a) Intrinsic motivation (IM): Is the most self-determined level of motivation that an individual can reach. This form of motivation can be defined as the desire to carry out an activity for the pleasure and satisfaction inherent in the practice of this activity $[18,19]$. This commitment is generally voluntary and can be explained by the personal interest that the activity represents for the individual [4]. In the field of education, it can be explained by a natural and innate tendency of the student to explore new knowledge and skills and meet new challenges [20]. The student is intrinsically motivated when he/ she performs voluntarily an activity that he / she interested in. This type of motivation is derived from the student's need to feel competent and self-determined $[21,1]$. 
According to Vallerand and Blais (1987) [22], there are three types of intrinsic motivations: the intrinsic motivation for knowledge, fulfillment and stimulation. In this research, these three forms of intrinsic motivations are integrated into one element since they are strongly correlated [23].

b) Extrinsic motivation (EM): This form of motivation is considered as an external charge related to all that is bonus and reward. According to Deci and Ryan (1985) [1], extrinsic motivation refers to involvement in an activity for a purpose not inherent in the activity, either to remove something pleasant, or to avoid something unpleasant, once the activity is over.

According to Deci and Ryan $(2002,2008)$ [24, 17], the extrinsic motivation is sub-divided into four types of motivations based on the degree of interiorization of the reasons or causes that drive the individual to perform an activity. Among these, Vallerand and al. (1989) [4], retain only three forms classified from the highest to the lowest degree of self-determination, namely: the identified regulation; introjected regulation and external regulation.

The first extrinsic motivation has internal motives for commitment, while the two latter ones have external motives for commitment.

- Motivation with identified regulation: Is a form of regulation in which the behavior of the individual depends not only on his / her interest in a given activity, but also on the intended purpose of the activity. It implies that « the subject performs the activity because he / she considers it a worthwhile activity and recognizes the importance of his commitment» [3] (p.62). As a result, he / she then estimates whether the activity is useful or not and freely chooses to perform it in order to achieve his / her personal goals [25].

- Motivation with introjected regulation: This type of motivation implies that the individual performs an activity «to avoid negative feelings, such as guilt, or to seek the approval of others» [26] (p.29). As a result, the person gradually internalizes the sources of control that were previously external to him / her. The resulting behaviors are experienced as relatively restrictive, but the individual must respect them in order to avoid feelings of guilt [27].

c) Motivation with external regulation: The most striking feature of this form is that the individual is motivated «by elements external to the activity such as material rewards or the avoidance of punishments» [3] (p.61). In this case, the individual performs an activity under the influence of external pressure such as the fear of punishment, the search for a reward, or controlled by a supervisor. The commitment is completely dependent on the presence of these external factors, as soon as they disappear; participation fades [28].

d) Amotivation: It can be defined by «the absence of any motivations in the individual» [3] (p.61). This type of motivation shows that the individual does not perceive any link between his / her behaviors and the consequences that may arise. 


\subsection{Interactive quizzes of formative nature to promote self-determined motivation}

The use of interactive quizzes is not likely to support student motivation if they return to the traditional concept of evaluation with grade. In addition, the quiz within a perspective of formative evaluation that requires especially the memorization, intellectual activity located at the base of the taxonomy of Bloom, through five types of items [29]: short answer, long answer, multiple choices, true-false, and matching. Certainly, they can motivate students to do the activities to gradually learn pedagogical content for the quiz [30]. In fact, the formative evaluation is among the most effective learning approaches, regardless of the subject area explored [31]. It aims to measure learners' level of achievement and difficulties to give feedback to the teacher and the student [32]. It can be considered as a lever to support and develop the selfregulation of learners' learning [33, 34], in addition it constitutes a relevant help for teachers in order to regulate the teaching / learning process [35]. It is through repeated formative evaluation and at different degrees of difficulty that learners will come to develop their autonomy. Awareness of their own judgment encourages them to redo the activity and focus on learning [36]. Moreover, the use of technologies to make the formative quizzes is a key skill to enable students to be more successful in an educational context [7, 37] and to be motivated to learn [38]. For example, the integration of ICT into the learning of university students may help motivate them if they feel more self-determined, more competent or if learning with ICTs increases their sense of affiliation [3].

\section{Practical Framework}

\subsection{Methodology}

It is to be remembered that the main goal of this research is to determine the level of self-motivation of students in the evaluation quizzes using Moodle as a platform for formative assessment. For this purpose, we opted for a quantitative approach to collected data. We present in this section the approach followed, the field of study, the target audience, the instrument used, and the techniques used to collect and process data.

The digital environment for formative assessment and the scenario adopted: To answer our problematic, we have designed a digital formative assessment space on Moodle to provide effective help to produce evaluation situations that will allow each learner to know at any time where he or she is in the construction of knowledge, as the course progresses. The scenario is based on the implementation of face-to-face courses " in-person classes" and series of tests in the form of quizzes filled in under Moodle after each course. Access is limited in time (one week to perform test) with only one attempt. Automatic feedbacks are also offered to students for continuous improvement of learning. 
The experimentation was conducted for the teaching of the Language and Terminology classes for the first and second Semester in the academic year 2018-2019.

During in-person classes, students follow the course with the teacher and after each class, students are invited to perform the distance learning quizzes via Moodle. With a total of 13 tests for the first semester and 10 tests for the second semester.

The questions in each test range from 10 to 26 questions depending on the content being evaluated.
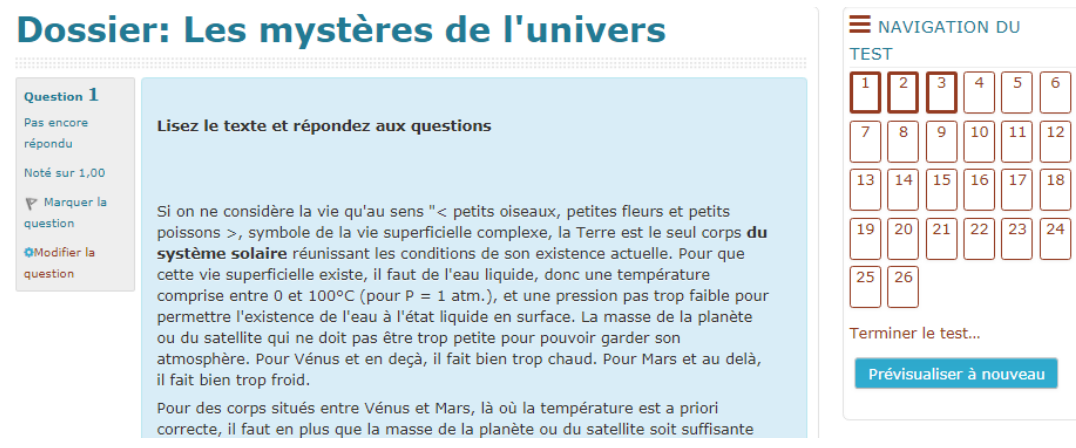

Fig. 1. Screenshot shows the number of questions (26) proposed in this quiz

In addition to the formative tests, courses and their supplements such as a glossary in relation with the themes of the subjects, are available on the platform to give students all the necessary media for learning and performing quizzes.

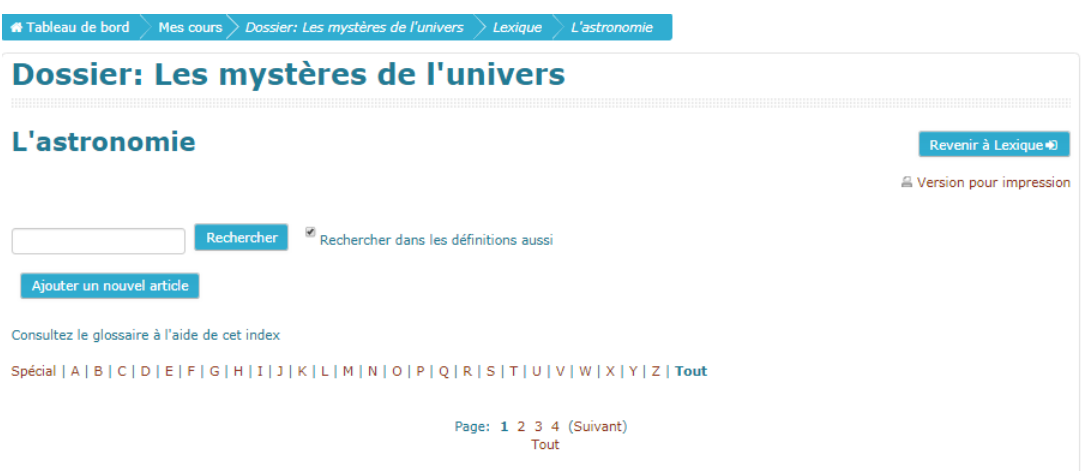

Fig. 2. Screenshot shows a glossary in relation to the theme of the universe

In summary, four steps characterize our formative assessment scenario:

- Creation of formative assessment tests (Moodle): To evaluate the achievement level of students, defined tests are created and associated with activities in relation to the notions of the course.

- Perform learning activities in class before the test: Students perform activities aiming to achieve the objectives of the course before taking the test. 
- Formative distance assessment with feedbacks: The students take a quiz, automatic feedbacks adapted to their results advices on activities to complete the study

- Regulation for improving and completion of the study: The students examine the test feedbacks and complete their lessons according to the instruction given.

The types of quizzes proposed: We proposed to the students quizzes in the form of multiple choice questions (MCQs), True / False, open questions with short answers, mad libs, drag and drop on text and matching.

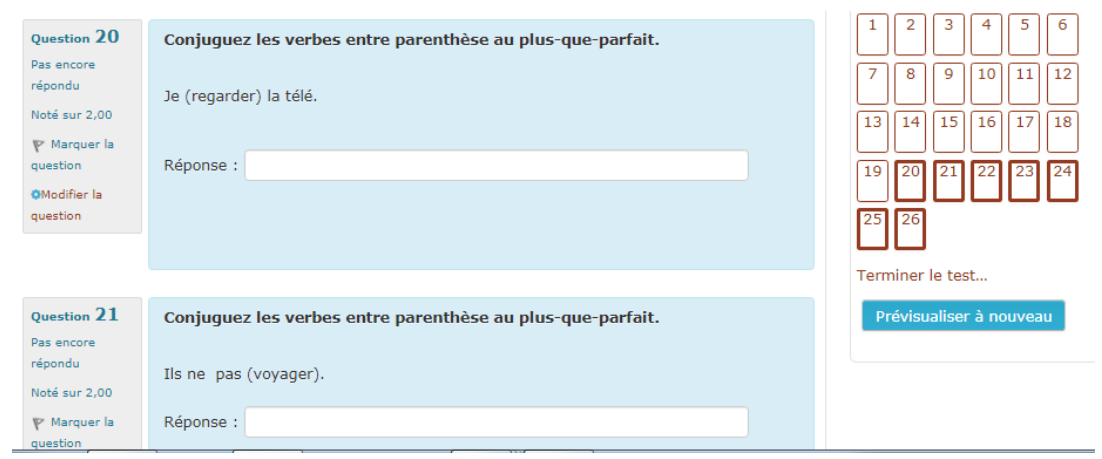

Fig. 3. Screenshot of an open short-answer question where the student can enter the answer as a word.

Measuring instrument and data collection: We chose as a reference the scale of motivation in education $[4,5]$. This scale evaluates the various forms of motivation proposed by the self-determination theory $[1,2,3]$. We developed a short scale (18 items) that contains five subscales: intrinsic motivation for learning (IM, for example, "because I have fun doing it."), Three subscales evaluated the extrinsic motivation, is extrinsic motivation with identified regulation (IDEN, for example, "because I think that technology will help me better understand the notions of course."), the extrinsic motivation by introjected regulation (INTRO, for example, "I do the activities on the platform to prove to me that I am an intelligent person that is able to learn by means of the platform") and the extrinsic motivation by external regulation (EXT, for example, "allows me to work better."). Finally, a subscale evaluated amotivation (AMO, for example, "I do not understand the relevance of doing activities on the platform"). A total of 18 items, including three items for the extrinsic motivation subscale, six for the extrinsic motivation by identified regulation, three for the extrinsic motivation by introjected regulation, three for the extrinsic motivation by external regulation, and three for the subscale, evaluated the amotivation.

The items describe possible reasons for doing the activities on the platform. Participants indicate their degree of agreement with the statements using a Likert-type scale ranging from 1 (they do not agree with) to 7 (they agree entirely with). Participants 
have been formed on the scale one week before the end of semesters 1 and 2 via the Moodle platform.

Sample: This experiment was carried out for the teaching of the module "Language and Terminology" within the Faculty of Sciences Ben M'sik. Casablanca.

The subjects that make up our sample are 112 and are students enrolled in the first year of the same university:

- A group of students enrolled in the earth, life and universe sciences department (SVTU) in Semester 1 for the 2018-2019 academic year.

- A group of students, enrolled in the Physical Sciences (SMP) in Semester 2, for the 2018-2019 academic year.

\subsection{Presentation and analysis of the results}

Reliability of the measuring instrument: We appreciate the internal consistency of the scales using Cronbach's alpha coefficient (1951) [39]. This one allows totest the coherence of each item with all the other statements of the scale to which it belongs [40] (p.183). For exploratory research, a coefficient of 0.5 or 0.6 may be considered acceptable [40]. In this study, the indices of internal coherence of subscales range from 0.54 to 0.85 :

Table 1. Cronbach index

\begin{tabular}{|l|c|}
\hline \multicolumn{1}{|c|}{ Dimension of motivation } & Cronbach's Alpha \\
\hline The intrinsic motivation for learning (IM) & $\alpha=0,69$ \\
\hline The extrinsic motivation by identified regulation (IDEN) & $\alpha=0,83$ \\
\hline The extrinsic motivation by introjected regulation (INTRO) & $\alpha=0,78$ \\
\hline The extrinsic motivation by external regulation (EXT) & $\alpha=0,54$ \\
\hline The amotivation (AMO) & $\alpha=0,85$ \\
\hline
\end{tabular}

All of Cronbach's alpha coefficients (Table 1) demonstrate a very acceptable reliability of the subscales of our measuring instrument. Thus, it's a coherent instrument from a measurement point of view

Average score for student motivation: The results of student motivation calculated through the analysis of the questionnaire are summarized in Table 2 and classified by type of motivation.

Table 2. Representation of the average score for student motivation

\begin{tabular}{|l|l|c|}
\hline \multicolumn{2}{|c|}{ Types of motivation } & Average score \\
\hline Intrinsic motivation (IM) & MI & 4,82 \\
\hline \multirow{3}{*}{ Extrinsic motivation (EM) } & The identified regulation (IDEN) & 4,94 \\
\cline { 2 - 3 } & The introjected regulation (INTRO) & 4,85 \\
\cline { 2 - 3 } & The external regulation (EXT) & 4,73 \\
\hline Amotivation & AMOT & 2,91 \\
\hline
\end{tabular}


Table 2 shows that the identified regulation motivation score is higher than all other types of continuum motivation, which implies a preponderance of students' allocated autonomous motivation [41, 42]. For Deci and Ryan (1985, 1991, 2000) [1, 2, 3] and Karsenti and Larose (2001) [9], these self-determined motivations foster greater interest in learning among students.

As for intrinsic motivation, students scored 4,82. This value shows that students are engaged in performing online quizzes for the sake of pleasure and satisfaction they feel when they are learning new things through the platform.

As for motivation by identification (IDEN), students obtained a score equal to 4,94 . This result shows that learners are engaged in performing the quizzes because they think that this learning activity is important enough to achieve their long-term personal goals such as passing the final exam. As for the introjected regulation (INTRO), the students obtained a score of 4,85 . This result shows that there were internal pressures that drive students to perform this learning activity such as fear and feeling of guilt.

As for the extrinsic motivation with external regulation (EXT), the study shows that students obtained a score of 4,73. This value shows that students 'behavior is regulated by external sources of control such as the personal goals they have already set at the beginning of the activity (having a good score on the final exam), and the teachers' feedbacks and encouragements.

Finally, for amotivation (AMOT), the sore obtained is 2,91. This value could characterize the discouragement observed among some students. It could also be explained by the fact that learners face a new learning environment they have never been used to it or by technical problems.

\section{Discussion}

The values taken from the external regulation $(4,73)$ and the introjected regulation $(4,85)$ remain close to remain close to those obtained through identified regulation $(4,94)$. This means that, while the students are engaged in carrying out learning activities that they think are an important tool for achieving their personal goals (selfdetermined), they feel, on the one hand, obliged to do, since they will be rewarded (external regulation) and, on the other hand, because of internal pressures, they have decided to carry out the learning activities (introjected regulation). The study showed that the use of the platform as a means of formative assessment in teaching the language and terminology courses has increased students' feelings of self-determination. This conclusion comes to confirm the results other research we conducted on the assessment of the learners' behavioural commitment with regards to the realization of formative quizzes, this assessment relied on the analysis of trace files provided by Moodle. The choice of indicators is based on the motivation model in the educational context of [43]. We have adopted measurable and observable indicators in the digital context such as: participation and punctuality in the performance of the evaluation tests, the number of attempts (the effort) and the follow-up and completion of tests.

The data that we have collected from the traces of assessment (manifestations of behavioural commitment) show that students are positively committed themselves to 
perform the quizzes. In addition, the formative evaluations that are based on ICTs promote positive behavioral commitment among students [44].

\section{Conclusion}

The analysis of all the data collected showed a positive level of self-determination among students engaged in performing online quizzes, this leads us to the conclusion that ICT learning through the Moodle platform has promoted a sense of selfdetermination among students and created favorable conditions for learning.

This perception of students that establishes the positive impact of using these quizzes on their self-determination broadly implies the crucial role of pedagogical practices that mobilize ICTs on both learning and academic performance.

Finally, it should be pointed out that the limits of this research depend primarily on two criteria, namely the sample size and the number of motivational tests carried out. With regard to sample size, the few number of respondents to the questionnaire obliges us to limit our conclusions concerning the results obtained. As for the number of motivational tests performed, only one test was performed at the end of the experiment. It would have been more interesting to plan several motivational tests spread over different periods during this study (for example, at the beginning, the middle and at the end of the experiment) in order to better improve the monitoring of motivation among learners.

\section{References}

[1] Deci, E. L. et Ryan, R. M. (1985). The General Causality Orientations Scale: SelfDetermination In Personality. Journal of Research in Personality, 19, 109-134. https://doi. org/10.1016/0092-6566(85)90023-6

[2] Deci, E. L. et Ryan, R. M. (1991). A Motivational Approach to Self: Integration in Personality. Dans R. Dienstbier (dir.), Actes du colloque de Nebraska sur la motivation. (vol.38, p237-288). Lincoln: University of Nebraska Press.

[3] Deci, E. L. et Ryan, R. M. (2000). Self-Determination Theory and the Facilitation of Intrinsic Motivation, Social Development, and Well-Being. American Psychologist, 55, 6878. https://doi.org/10.1037/0003-066x.55.1.68

[4] Vallerand, R. J., Blais, M. R., Briere, N. M. and Pelletier, L. G. (1989). Construction and validation of the Education Motivation Scale (EMS). Canadian Journal of Behavioral Science, 21, 323-349. DOI : 10.1037/h0079855

[5] Vallerand, R. J. and Thill, E. E. (dir.). (1993). Introduction to the psychology of motivation. Laval, QC : "Études Vivantes" Editions.

[6] Poyet, F. (2011). School culture and digital culture in tension. In F. Poyet (dir.), Education in the digital age: situational analysis, issues and perspectives (p. 29-44). Lyon, France : ENS-INRP.

[7] Karsenti, T. (2006). How to promote the success of African students in open and distance learning (foad): pedagogical principles. TICE and development, Ob. Extracted from http:// www.revue-tice.info 
[8] Lapierre, J. \& Ginggras.G (2001). Perception of professors and students on the use and impact of ICT at École polytechnique de Montréal. Department of Mathematics and Industrial Engineering, École Polytechnique de Montreal. https://doi.org/10.14332/svc15.proc. $\underline{1982}$

[9] Karsenti, T. and Larose, F. (2001). ICT at the heart of university pedagogies. Quebec: University of Quebec Press.

[10] Margaryan, A., Nicol, D., Littlejohn, A. et Trinder, K. (2008). Students Use of Technologies to Support Formal and Informal Learning. Dans J. Luca et E. Weippl (dir.), Proceedings of World Conference on Educational Multimedia, Hypermedia and Telecommunications (ED-MEDIA). (p. 4257-4266). Chesapeake, VA: Association for the Advancement of Computing in Education (AACE).

[11] Strategic vision of the reform 2015/2030: For a school of equity, quality and of the promotion. Extracted from: https://www.csefrs.ma/wp-content/uploads/2017/09/Vision_VF_Fr_Resume.pdf.

[12] Pintrich, P.R. (2003). A motivational science perspective on the role of student motivation in learning and teaching contexts. Journal of Educational Psychology, 95, 667-686. https:// doi.org/10.1037/0022-0663.95.4.667

[13] Pintrich, P. R., \& Schunk, D. H. (2002). Motivation in Education. Englewood Cliffs, NJ: Prentice Hall.

[14] Karsenti, T. (1997). How can the use of ICT in the university pedagogy promote student motivation: the case of a web-based course. New specification of Education Research, 4(3), 455-484. DOI : 10.7202/1017306ar.

[15] Pinder, C.C. (1984), Work motivation/theory, issues, and applications, Glenview, Ill. Scott : Foresman

[16] Viau, R. (1995). Motivation in school environment. French Journal of Pedagogy, 113, 154155. Link: Extracted from: http://www.persee.fr/docAsPDF/rfp 055678071995 num 113_1_2992_t1_0154_0000_2.pdf

[17] Deci, E. L. and Ryan, R. M. (2008). Promote optimal motivation and mental health in the various living environments. Canadian Psychology, 49(1), 24-34. Extracted from: https:// doi.org/10.1037/0708-5591.49.1.24

[18] Deci, E. L. (1971). Effects of Externally Mediated Rewards on Intrinsic Motivation. Journal of Personality and Social Psychology, 18, 105-115. Extracted from: https://doi.org/10. $1037 / \mathrm{h} 0030644$

[19] Vallerand, R. J. and Halliwell, W. R. (1983). Contemporary theoretical formulations in intrinsic motivation. Review and critique. Canadian Psychology, 24, 243-256. https://doi. org/10.1037/h0080748

[20] Spinath, B., \& Steinmayr, R. (2012). The roles of competence beliefs and goal orientations for change in intrinsic motivation. Journal of Educational Psychology, 104(4), 1135-1148. Extracted from: https://doi.org/10.1037/a0028115

[21] Deci, E. L. (1975). Intrinsic motivation. New York, NY : Plenum Press.

[22] Vallerand, R. J. and Blais, M. R. (1987). Towards a Tripartite Conceptualization of Intrinsic Motivation: Intrinsic Motivation for Knowledge, Accomplishment and Sensations (Unpublished Manuscript, Social Psychology Laboratory, University of Quebec, Montreal)

[23] Litalien, D. (2008). Why rural students show lower educational aspirations than those from urban areas-An Explanation Based on a Motivational and Relational Perspective (Master's thesis not published). Quebec: Laval University.

[24] Deci, E. L. et Ryan, R. M. (2002). Handbook of selfdetermination research. Rochester, NY: University of Rochester Press. 
[25] Rodrigue, I. (2013). The motivation to write and the writing performance of girls and boys in Secondary 1 (Master's thesis not published). University of Quebec, Montreal.

[26] Biddle, S., Chatzisarantis, N., \& Hagger, M. (2001). Self-determination theory in the field of sport and exercise. In F. Cury and P. Sarrazin (Eds.), Theories of Motivation and Sports Practice. State of Research (pp. 19-55). Paris: PUF.

[27] Fiorello, A. and Luu, P. (2014). Promoting sustainable change and behavior: The contributions of self-determination theory. an application to the sorting behavior of household waste. French marketing magazine, 249, 37-64.

[28] Ryan, R. M., \& Deci, E. L. (2007). Active human nature: Self-determination theory and the promotion and maintenance of sport, exercise, and health. In M. S. Hagger \& N. L. D. Chatzisarantis (Eds.), Intrinsic motivation and self-determination in exercise and sport (pp. 1-19). Leeds, UK: Human Kinetics Europe. https://doi.org/10.1016/j.psychsport.2007. $\underline{06.003}$

[29] Raynal, F. and Rieunier, A. (1998). Pedagogy: dictionary of key concepts. Paris: ESF Editeur.

[30] Ramsden, P. (1988). Improving learning: New perspectives. London : Kogan Page.

[31] Silvestre, F. (2015). Design and implementation of a formative evaluation system for faceto-face courses in higher education (unpublished Phd thesis). Toulouse 3 Paul Sabatier University.

[32] Eberly Center, C. M. U. (2015). What is the difference between formative and summative assessment ? https://www.cmu.edu/teaching/assessment/basics/formative-summative.html. Accessed : 2015-07-27. https://doi.org/10.1142/9789812795472_0028

[33] Clark, I. (2012). Formative assessment: Assessment is for self-regulated learning. Educational Psychology Review, 24(2), 205-249. https://doi.org/10.1007/s10648-011-9191-6

[34] Wiliam, D. (2010). An integrative summary of the research literature and impicatios for a new theory of formative assessment. In H. A. Andrade \& G. J. Cizek (Eds.), Handbook for formative assessment (pp. 18-40). New York: Routledge.

[35] Allal, L., Mottier lopez, L. (2005). Formative assessment of learning: a review of publications in French. in OECD, Formative Assessment: Improving Learning in Secondary Classrooms (pp. 241-264). Paris, France: OECD Publishing. https://doi.org/10.1787/9789 264007413-sum-it

[36] Talbot, L. (2009). Formative Evaluation: How to Evaluate to Remedy Learning Difficulties. Paris: Human and social sciences, (1st ed. 2009).

[37] Karsenti, T. and Collin, S. (2013). When ICTs hit the target; Their impact on student commitment. Education Canada, 53, 53(1). Extracted from http://cea-ace.ca/education-ca nada

[38] Viau, R. (2009). The Motivation in school environment (2e éd.). Brussels, Belgium: De Boeck

[39] Cronbach, L. J. (1951). Coefficient alpha and the internal structure of tests. Psychometrika, 16(3), 297-334. Extracted from https://doi.org/10.1007/bf02310555

[40] Jolibert, A., \& Jourdan, P. (2006). Marketing research. Méthodes de recherche et d'études en marketing. Paris : Dunod.

[41] Heutte, J. (2016a, February). Homo sapiens retiolus : contribution to the ecology of learning communities. Paper presented at the ANR Translit Intermediate Colloquium "Transliteracy and Digital Affiliations", Bordeaux, France.

[42] Heutte, J. (2017). The persistence of motivation and the experience of Flow: a reference framework for the study of e-learning. In O. Las Vergnas (eds.), Informal e-learning. Paris, France: editions of contemporary archives.

[43] Viau, R. (1994). Motivation in school context (3rd Ed.). Brussels : De Boeck University. 
[44] Chemsi, G., Sadiq, M., Radid, M., Talbi, M. (2019). Formative E-Assessment and Behavioral Commitment of Students: Case of the Faculty of Science Ben M'sik. International Journal of Emerging Technologies in Learning (iJET) 14(12): p4-14. 11p. https://onlinejournals.org/index.php/i-jet/article/view/10389/5744. https://doi.org/10.3991/ijet.v14i12.10 $\underline{389}$

\section{$7 \quad$ Authors}

Ghizlane Chemsi: is a PhD in Educational Technology. She is a Professor at Faculty of Sciences Ben M'Sik, University Hassan II of Casablanca, Morocco, B.P 7955 Sidi Othmane. She operates in several fields of educational sciences: educational technologies and assessment, engineering of assessment. She is a Member of the Observatory of Research in Didactics and University Pedagogy (ORDIPU), Member of Association for the Development of Evaluation Methodologies in Education (ADMEE) - section Morocco and the Multidisciplinary Laboratory in Sciences and Information Communication and EducationTechnology (LAPSTICE).

Mounir Sadiq is a PhD in Educational Computing. He is operates in several fields of educational sciences: the fields of teaching and research on educational technologies, engineering of the distance training, techniques of training. He is a Member of the Observatory of Research in Didactics and University Pedagogy (ORDIPU) and Member of Association for the Development of Evaluation Methodologies in Education (ADMEE) - section Morocco.

Mohamed Radid is a PhD in Physical Chemistry. He is currently the Vice Dean of the Faculty of Sciences Ben M'Sik at Hassan II University, B.P 7955 Sidi Othmane, Casablanca, Morocco since 2014. He is a Member of the Observatory of Research in Didactics and University Pedagogy (ORDIPU) and Member Board of Directors of Association for the Development of Evaluation Methodologies in Education (ADMEE) - Europe. He is an Expert in the fields of teaching and research on educational and technologies assessment, engineering of assessment, Chemistry Didactics, University Pedagogy.

Mohammed Talbi is a PhD in Sciences and Processes of Analysis from the University Pierre et Marie Curie of Paris. He is currently the Dean of the Faculty of Sciences Ben M'Sik at Hassan II University, B.P 7955 Sidi Othmane, Casablanca, Morocco since 2014, and the Director of the Observatory of Research in Didactics and University Pedagogy (ORDIPU). He is an Expert in the fields of teaching and research on educational technologies, engineering of the distance training, techniques of training, information systems. He is the author of several national and international awards and has accumulated more than 30 years of scientific productions.

Article submitted 2019-07-28. Resubmitted 2019-11-19. Final acceptance 2019-11-23. Final version published as submitted by the authors. 